\title{
Influence of different types of whitening tooth pastes on the tooth color, enamel surface roughness and enamel
}

\section{morphology of human teeth [version 1; peer review: 3}

\section{approved]}

\author{
Mohamed Shamel(D1, Mahmoud M. Al-Ankily (D)1, Mahmoud M. Bakr (D2 \\ ${ }^{1}$ Oral Biology Department, The British University in Egypt, Cairo, Egypt \\ ${ }^{2}$ School of Dentistry and Oral Health, Griffith University, Mount Gravatt, Queensland, 4222, Australia
}

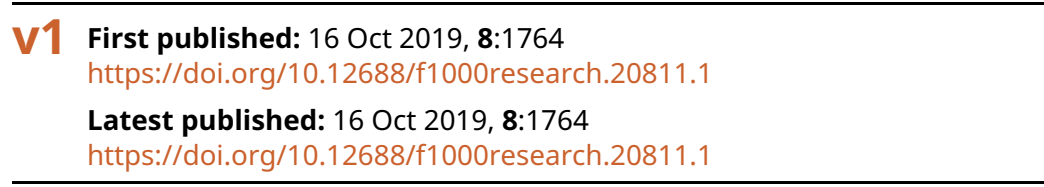

\section{Abstract}

Background: Tooth whitening usually includes the direct use of gels containing carbamide or hydrogen peroxide on the tooth enamel surface through a wide variety of products formulas. A generally new advancement in whitening of teeth uses the significant importance of the tooth color shift from yellow to blue in delivering a general enhancement in the observation of tooth whiteness. The aim of the current work was to measure the tooth whitening effects, surface roughness and enamel morphology of six different types of blue covarine-containing and blue covarine-free toothpastes using in vitro models.

Methods: A total of 70 sound extracted human premolars were randomly and equally divided into seven groups, and each subjected to tooth brushing using different toothpastes. Tooth color and enamel surface roughness were measured before and after the brushing procedure using a white light interferometer, and scanning electron microscopy (SEM) was used to assess tooth surface after the procedure.

Results: Toothpaste containing blue covarine resulted in the greatest improvement in tooth color amongst all groups as well as a statistically significant color difference when compared to blue covarine-free toothpaste. Furthermore, blue covarine-containing toothpaste resulted in fewer morphological changes to the enamel surface. This was confirmed with SEM images that showed smooth enamel surfaces with fine scratches.

Conclusions: The results from the present study show that blue covarine containing toothpastes are reliable, effective in tooth whitening and produce less surface abrasion when compared to blue covarine-free toothpastes.

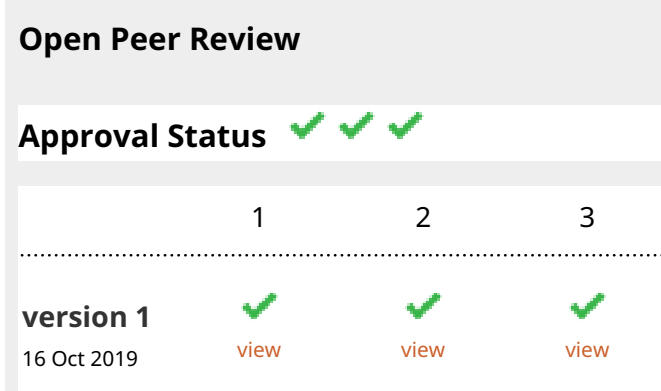

1. Rania Mossad Hassan, Ain Shams University,

Cairo, Egypt

Badr University, Cairo, Egypt

2. Mahmoud Serag, East Carolina

University (ECU), Greenville, USA

3. Rizwan Ullah, Jinnah Sindh Medical

University, Karachi, Pakistan

Any reports and responses or comments on the article can be found at the end of the article. 
Keywords

Tooth whitening, Blue covarine, Enamel, tooth color, enamel surface

roughness, SEM

Corresponding author: Mohamed Shamel (mohamed.shamel@bue.edu.eg)

Author roles: Shamel M: Project Administration, Supervision, Writing - Original Draft Preparation, Writing - Review \& Editing; Al-Ankily MM: Investigation, Methodology, Supervision, Writing - Review \& Editing; Bakr MM: Funding Acquisition, Supervision, Validation

Competing interests: No competing interests were disclosed.

Grant information: The author(s) declared that no grants were involved in supporting this work.

Copyright: @ 2019 Shamel $\mathrm{M}$ et al. This is an open access article distributed under the terms of the Creative Commons Attribution License, which permits unrestricted use, distribution, and reproduction in any medium, provided the original work is properly cited.

How to cite this article: Shamel M, Al-Ankily MM and Bakr MM. Influence of different types of whitening tooth pastes on the tooth color, enamel surface roughness and enamel morphology of human teeth [version 1; peer review: 3 approved] F1000Research 2019, 8:1764 https://doi.org/10.12688/f1000research.20811.1

First published: 16 Oct 2019, 8:1764 https://doi.org/10.12688/f1000research.20811.1 


\section{Introduction}

Patients are generally dissatisfied with their present teeth color, as demonstrated by many studies in different regions of the world ${ }^{1-6}$. This is most evident from the expanded interest for orthodontic treatment and for using products, either in office or at home, for whitening of teeth ${ }^{7}$.

Attempts to improve the shade of teeth is presently possible using multiple methods, including professional scaling and prophylaxis performed in the dental clinic, fabrication of tooth crowns and laminate veneers and the use of tooth-whitening toothpastes ${ }^{8}$. Tooth-whitening formulations work by one of two different methods, either by the elimination of extrinsic tooth stain or by bleaching of the tooth itself ${ }^{9}$.

Tooth whitening usually includes the direct use of gels containing carbamide or hydrogen peroxide on the tooth enamel surface and are available in a wide variety of products formulas. The peroxide moves into the enamel structure to brighten any internal discoloration and hence making the teeth look whiter. Nonetheless, the efficient delivery of peroxides from the toothpaste to the tooth is multifactorial, including design factors, controlling boundaries and the comparatively limited contact periods during brushing ${ }^{9,10}$.

Historically, one of the main components in toothpastes used for whitening has been abrasives, which help to eliminate extrinsic stains as well as prevent their formation. A wide range of other components is usually added to this abrasive system, such as surfactants, calcium chelators, polymers and enzymes; however, evidence indicates that the abrasive is the most crucial component in the toothpastes for stain removal ${ }^{11,12}$. Yet, there are worldwide governing limitations on the maximum levels of abrasives allowed in any toothpaste and thus there is some restrictions to how much whitening can be effectively and (most importantly) safely obtained through abrasive advancements ${ }^{8}$.

To numerically evaluate color, a system was suggested by the International Commission on Illumination (CIE) in 1976 which consisted of three different coordinates designed as $\mathrm{L}^{*}$, $a^{*}$ and $b^{*}$. Any color is totally identified by three coordinates: $\mathrm{L}^{*}, \mathrm{a}^{*}$ and $\mathrm{b}^{*}$. $\mathrm{L}^{*}$ values range from 0 to 100 and denotes darkness/brightness; $\mathrm{a}^{*}$ represents the green-red component, with values ranging from -80 (green) to +80 (red); and $b^{*}$ represents the blue-yellow component, with values ranging from -80 (blue) to +80 (yellow) $)^{13}$.

A generally novel advancement in tooth bleaching utilizes the importance of the tooth color change from yellow to blue (i.e. a decrease of $b^{*}$ values) in obtaining a general enhancement in the observation of whiteness of teeth ${ }^{14}$. The theory is reinforced by tooth whitening studies that show that the change in color from yellow to blue represents significant evidence of tooth whitening and that a decrease in the value of $b^{*}$ color parameter is a crucial factor for tooth whitening recognition by patients ${ }^{15,16}$. Using previous optical theories, a toothpaste containing a blue pigment, named blue covarine, was introduced. This paste applies the blue pigment onto the tooth enamel during daily cleaning procedures using toothbrushes, changing tooth color from yellow to blue. Several clinical and in vitro studies confirmed that this increase in bluish color and decrease in yellow color makes the teeth look whiter immediately after tooth brushing ${ }^{17,18}$.

Blue covarine-containing tooth pastes have been additionally improved by supplementing the concentration levels of blue pigment, so as to furtherly improve the optical tooth whitening advantage ${ }^{14,19}$. The aim of the current study was to measure the tooth whitening effects, surface roughness and enamel morphology of six different types of blue covarine-containing and blue covarine-free toothpastes using in vitro models.

\section{Methods}

\section{Samples}

A total of 70 sound extracted human premolar teeth, obtained for purposes of research with informed consent. The study was approved by the Research Ethics Committee at Suez Canal University (approval number Suez- REC 27/2018), where this research was performed. The enamel surfaces were then cleaned with prophylactic paste to ensure elimination of extrinsic stains. The teeth were kept in sterilized artificial saliva for two hours. Teeth were mounted in gypsum blocks by embedding the roots and the lingual half, where the middle part of the middle one-third of the buccal aspect is the highest area of the specimen.

The specimens ( $\mathrm{n}=10$ per group) were randomly distributed to the tested toothpastes which were as follows:

Group I: Close up White now (Unilever, São Paulo, Brazil) (with blue covarine)

Group II: Sensodyne True White (GSK, UK) (whitens by abrasion/sodium triphosphate)

Group III: Colgate Optic White (Colgate-Palmolive, USA) (whitens by abrasion/sodium monophosphate with hydrogen peroxide)

Group IV: Close Up (Unilever, São Paulo, Brazil)

Group V: Sensodyne (GSK, UK)

Group VI: Colgate (Colgate-Palmolive, USA)

Group VII: Control: No tooth paste application

Groups I and IV have the same formulation (sodium fluoride), but the former has an additional whitening ingredient. The same is true for groups II and V (potassium nitrate), and III and VI have the same formulation (sodium fluoride), but the former have an additional whitening component. Thus, groups IV, V and VI serve as non-whitening controls for groups I, II and III, respectively.

\section{Color measurement}

The three parameters of color of each specimen were measured using a VITA Easyshade spectrophotometer Advance 4.01 (VITA Zahnfabric, Bad Sackingen, Germany) according to the 
CIE L*a*b* color order system. Mean measurements of the middle part of the middle one-third of the buccal aspect were recorded.

\section{Surface roughness measurement}

The Baseline surface roughness was studied using Zygo Maxim GP-200 white light interferometer (Artisan Technology Group, Illinois, USA) with a surface area $2 \mathrm{~mm} \times 2 \mathrm{~mm}$. Surface roughness was quantified as deviation from the ideal surface in $\mu \mathrm{m}$ using white light interferometer. Mean measurements of the middle part of the middle one-third of the buccal aspect were recorded.

\section{Brushing procedures}

For the purpose of standardization of the brushing procedure, a specially designed brushing apparatus was designed and fabricated (Figure 1). The brushing apparatus was set at 120 strokes/ min, and a load of $250 \mathrm{~g}$. For each experimental group, the specimens were fixed in the machine and brushed with a toothpaste corresponding to its group for 3.5 minutes, simulating 4 weeks of brushing three times a day. Every toothpaste was mixed with distilled water with a ratio of toothpaste: water $2: 1^{15}$. After tooth brushing, every specimen was rinsed in water to ensure removing all the toothpaste, and the teeth color was remeasured before they were restored in artificial saliva.

\section{Color measurement difference}

The change in color $\left(\Delta \mathrm{E}^{*}\right)$ was calculated as follows:

$$
\Delta \mathrm{E}^{*}=\left[(\Delta \mathrm{L} *)^{2}+(\Delta \mathrm{a} *)^{2}+(\Delta \mathrm{b} *)^{2}\right] 1 / 2
$$

where $\Delta \mathrm{L}^{*}, \Delta \mathrm{a}^{*}$, and $\Delta \mathrm{b}^{*}$ are the difference between the final and initial $\mathrm{L}^{*}, \mathrm{a}^{*}$, and $\mathrm{b}^{*}$ color parameters, respectively.

\section{Surface roughness difference}

Surface roughness measures after the brushing procedure were recorded and the difference between the baseline was calculated.

\section{Scanning electron microscopy (SEM) analysis}

Surface Morphology was studied using images obtained from SEM of one sample from each group after the brushing procedure. The specimens were rinsed ultrasonically with water for ten minutes and prepared for SEM (FEI, QUANTA FEG 250) analysis. After dehydration, enamel surfaces were sputter-coated with gold (approximately 30-35 $\mathrm{nm})$ and photomicrographs of representative areas were taken at $1000 x$ and 2000x magnifications. The classification for the enamel changes were as follows; no alterations, mild or slight alterations, significant alterations and loss of superficial structures.

\section{Statistical analysis}

All data was analyzed with the statistical program SPSS version 21 (SPSS Armonk, NY, USA). Data from baseline as well as from final measurements were analyzed using one-way analysis of variance (ANOVA) when there is only one factor, which is the type of toothpaste, and Tukey's test as a post hoc test. A paired Student's t-test was used to compare the initial and final color parameters for each experimental group.

\section{Results}

\section{Teeth color}

Results for initial and final color parameters for all specimens of all groups are tabulated in Table 1. One-way ANOVA revealed mean color changes which was statistically significant between groups $(p=0.01)$. The mean changes in color parameters which were informed by the International Commission on Illumination (CIELAB) values directly after brushing as well as difference in $b$ value alone showed that toothpaste containing blue covarine (Group I, Close Up White Now) gave the highest decrease in $b^{*}$, revealing a bluish change in the color of the teeth and thus the highest improvement in tooth whiteness correspondingly, while the control group showed the least reduction in $\mathrm{b}^{*}$ and tooth whiteness (Figure 2).

Toothpaste which contained blue covarine (Group I) had a color statistically significant difference compared with the nonwhitening control, group IV (Close up regular tooth paste) ( $\mathrm{p}=0.02$, Student's t-test) and also a statistically significant difference with other types of whitening tooth pastes not containing blue covarine group II $(\mathrm{p}=0.005)$ and group III $(\mathrm{p}=0.04)$, . Mean color changes of specimens treated with whitening blue covarine-free tooth pastes (groups II and III) showed a positive but statistically non-significant increase in

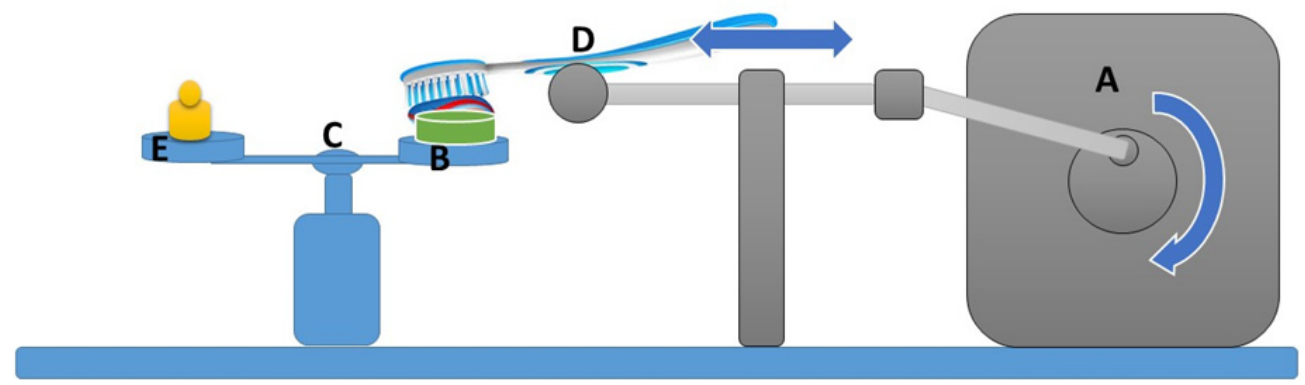

Figure 1. Diagrammatic drawing showing the brushing apparatus. The Brushing apparatus consists of: (A) a gear box to reduce the speed of the motor to 2 cycle/second with a crankshaft and connecting rod attached to a slider in order to change the rotation movement into linear movement to provide a standardized $5 \mathrm{~mm}$ horizontal movement; (B) a brush holder; (C) double-pane balance; (D) samples holding pane; and (E) weight holding pane. 

Table 1. Color parameters for specimens of all groups
before and after brushing.

\begin{tabular}{|c|c|c|c|c|c|c|c|}
\hline \multirow[t]{2}{*}{ Toothpaste } & \multirow[t]{2}{*}{ Sample } & \multicolumn{3}{|c|}{ Before } & \multicolumn{3}{|l|}{ After } \\
\hline & & $L^{*}$ & $a^{*}$ & $\mathbf{b}^{*}$ & $L^{*}$ & $a^{*}$ & $\mathbf{b}^{*}$ \\
\hline \multirow{10}{*}{$\begin{array}{l}\text { Closeup } \\
\text { white now }\end{array}$} & A1 & 83.7 & -1.9 & 20.8 & 84.8 & -2.2 & 18.6 \\
\hline & A2 & 75.8 & -1.5 & 19.6 & 77.3 & -2.3 & 16.5 \\
\hline & A3 & 79.8 & 1.4 & 26.1 & 73.9 & 0.5 & 22.6 \\
\hline & A4 & 83.6 & 0.9 & 40.5 & 86.1 & 0.2 & 33.2 \\
\hline & A5 & 83.1 & -2.3 & 30.5 & 80.1 & -1.2 & 30.4 \\
\hline & A6 & 87.3 & -1.4 & 21.8 & 94.6 & -2.8 & 21.5 \\
\hline & A7 & 73.7 & 0.3 & 27.8 & 77.4 & -2.2 & 18.8 \\
\hline & A8 & 79.8 & 1.3 & 27.3 & 77.2 & 1 & 25.4 \\
\hline & A9 & 82.1 & 0.9 & 40.1 & 76.3 & 0 & 21.3 \\
\hline & A10 & 84.6 & -1.4 & 33.5 & 81.2 & -1.7 & 30 \\
\hline \multirow{10}{*}{$\begin{array}{l}\text { Sensodyne } \\
\text { true white }\end{array}$} & B1 & 71.5 & -2.6 & 16 & 72.8 & -1.4 & 23.1 \\
\hline & B2 & 86.4 & -1.7 & 22.7 & 79.4 & -1.6 & 20.1 \\
\hline & B3 & 81.3 & 3.5 & 42.8 & 79.8 & 1.5 & 33.2 \\
\hline & B4 & 76 & 1 & 27.3 & 72.2 & 4.1 & 35 \\
\hline & B5 & 86.3 & 0.4 & 31 & 83 & 0.5 & 30.6 \\
\hline & B6 & 77.8 & -1.8 & 20.9 & 71.9 & -1.4 & 22.5 \\
\hline & B7 & 79 & -1.1 & 17.4 & 79.3 & -0.9 & 17.5 \\
\hline & B8 & 80.6 & -5 & 27.3 & 77.9 & -0.1 & 23.1 \\
\hline & B9 & 82.4 & -0.9 & 23.4 & 82.1 & -1.2 & 22.1 \\
\hline & B10 & 82.5 & -0.2 & 26.3 & 85.2 & -0.3 & 28.1 \\
\hline \multirow{10}{*}{$\begin{array}{l}\text { Colgate } \\
\text { optic white }\end{array}$} & C1 & 78.9 & -1.1 & 23.2 & 81.7 & -1.2 & 25.1 \\
\hline & $\mathrm{C} 2$ & 76.9 & -0.4 & 24.7 & 76.3 & -0.4 & 25.8 \\
\hline & C3 & 82.2 & -0.6 & 31.8 & 78.9 & -0.5 & 26.2 \\
\hline & $\mathrm{C} 4$ & 78.7 & -0.3 & 30.2 & 71.7 & -2.2 & 14.9 \\
\hline & C5 & 80.7 & -1.1 & 18.3 & 80.2 & -1.7 & 15 \\
\hline & $\mathrm{C} 6$ & 87.4 & -0.9 & 27.3 & 86.2 & -1 & 27.2 \\
\hline & $\mathrm{C} 7$ & 79.6 & -0.8 & 24.8 & 82.8 & -0.9 & 26.3 \\
\hline & C8 & 78.3 & -2.2 & 17.8 & 81.9 & -1.6 & 27.9 \\
\hline & C9 & 82.3 & -1.7 & 19.6 & 69.7 & -1.2 & 22.2 \\
\hline & C10 & 78.7 & -1.1 & 18 & 79.1 & -0.7 & 20.7 \\
\hline \multirow[t]{10}{*}{ Sensodyne } & E1 & 89.6 & -1.9 & 26.1 & 79.8 & -1.9 & 25.7 \\
\hline & E2 & 80.5 & -0.6 & 25.9 & 75.9 & -0.8 & 23.2 \\
\hline & E3 & 79.1 & -2.9 & 5.5 & 85.1 & -3.1 & 8.8 \\
\hline & E4 & 69.2 & -0.3 & 27.2 & 66.6 & -0.2 & 27.3 \\
\hline & E5 & 86.2 & 1.6 & 32.9 & 73.6 & 1.9 & 31.1 \\
\hline & E6 & 85.8 & -2.6 & 19 & 78.3 & -2.3 & 16.8 \\
\hline & E7 & 78 & 0.3 & 25.1 & 70 & -0.4 & 20.4 \\
\hline & E8 & 80.2 & -2.3 & 12 & 81.6 & -1.9 & 14.3 \\
\hline & E9 & 75.7 & -1.5 & 20 & 70.9 & -1.7 & 16.8 \\
\hline & E10 & 78.5 & -0.3 & 20.8 & 71.9 & 0 & 18.7 \\
\hline
\end{tabular}

\begin{tabular}{|c|c|c|c|c|c|c|c|}
\hline \multirow[t]{2}{*}{ Toothpaste } & \multirow[t]{2}{*}{ Sample } & \multicolumn{3}{|c|}{ Before } & \multicolumn{3}{|c|}{ After } \\
\hline & & $L^{*}$ & $a^{*}$ & $\mathbf{b}^{*}$ & $L^{*}$ & $a^{*}$ & $\mathbf{b}^{*}$ \\
\hline \multirow[t]{10}{*}{ Colgate } & F1 & 86.3 & -2.2 & 24.3 & 89.9 & -1.5 & 33.2 \\
\hline & F2 & 83.2 & -0.2 & 35.9 & 82.9 & 0.1 & 34.7 \\
\hline & F3 & 84.6 & -2.2 & 14.6 & 81.8 & -1.8 & 18 \\
\hline & F4 & 86.4 & -2.9 & 13 & 91.7 & -3.2 & 18.3 \\
\hline & F5 & 87.8 & 3 & 35.4 & 78.5 & 2.9 & 32.3 \\
\hline & F6 & 87.9 & -1.3 & 35.5 & 89.4 & -1.3 & 33.2 \\
\hline & F7 & 84.8 & 0 & 39.7 & 84.8 & -0.1 & 36.9 \\
\hline & F8 & 80.3 & -0.2 & 29.7 & 79.9 & -2.1 & 15.8 \\
\hline & F9 & 89.1 & -2.7 & 22.4 & 87.5 & -1.6 & 27.4 \\
\hline & F10 & 77.6 & 4.3 & 37 & 77.2 & 2 & 30.1 \\
\hline \multirow[t]{10}{*}{ Control } & G1 & 74.6 & 2.7 & 35.2 & 76.2 & 2.4 & 35.6 \\
\hline & G2 & 66.9 & 1.9 & 29 & 67.7 & 4.7 & 40.5 \\
\hline & G3 & 69.9 & 2.9 & 34.7 & 63.4 & 3.2 & 32 \\
\hline & G4 & 87.1 & -1.5 & 19.5 & 79.1 & -1.8 & 20.7 \\
\hline & G5 & 82.7 & -2 & 14.2 & 82.1 & -1.4 & 22.9 \\
\hline & G6 & 81.6 & -1.3 & 21.2 & 84.8 & -1.8 & 17.6 \\
\hline & G7 & 81.4 & -0.3 & 27.2 & 80.6 & -0.1 & 29.7 \\
\hline & G8 & 83.9 & -0.7 & 26.5 & 78.1 & -2.5 & 18.2 \\
\hline & G9 & 82.2 & -1.2 & 23.6 & 81.9 & -2 & 22.3 \\
\hline & G10 & 79.1 & 1.1 & 21.6 & 77.5 & -1.2 & 20.4 \\
\hline
\end{tabular}

the overall color change and a slight increase in the $b^{*}$ when compared to their non-whitening controls, groups $\mathrm{V}$ and VI, respectively ( $\mathrm{p}=0.08$, Student's t-test). Raw tooth color values for each group are available as Underlying data ${ }^{20}$.

\section{Surface roughness}

Results of surface roughness measurement of specimens of all groups are tabulated in Table 2. There were no statistically significant differences in the mean values of surface roughness difference $(\mathrm{Ra})$ of all groups $(\mathrm{p}=0.07)$. The control group showed the least surface roughness change, with a reduction in median $\mathrm{Ra}$ of $0.25 \mu \mathrm{m}$; the treatment with the toothpaste containing blue covarine (Group I) showed $\mathrm{Ra}$ value of 0.02 $\mu \mathrm{m}$; the Ra value of tooth paste of group II was $0.02 \mu \mathrm{m}$ while that of group III showed the highest $\mathrm{Ra}$ value of 0.53 (Figure 3 and Figure 4). Raw surface roughness values and white light interferometry images are available as Underlying data ${ }^{20,21}$.

\section{SEM examination}

Group I tooth samples revealed relatively smooth enamel surface with few fine scratches. Group II showed similar surface pattern with some fine scratches on the enamel surface when compared to control group, whereas tooth paste of group III caused greater alteration in enamel morphology manifested as surface irregularities, few pores and also the scratches became more obvious. Samples from groups IV, $\mathrm{V}$ and VI exhibited no noticeable differences regarding the 


\section{Mean changes in CIELAB}

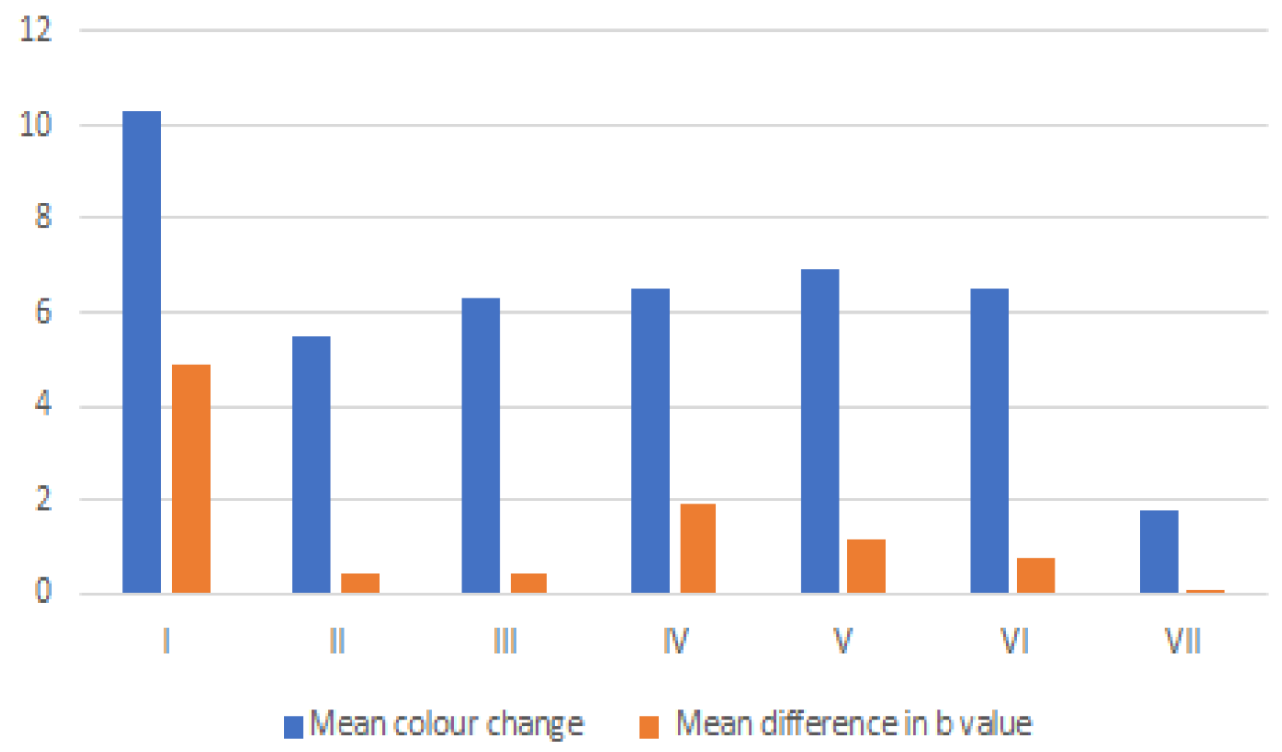

Figure 2. Showing mean changes in color values directly after toothbrushing as well as difference in $\mathbf{b}^{*}$ value.

morphology of the surface of the enamel in comparison to the control samples (Figure 5). Raw SEM images are available as Underlying data ${ }^{21}$.

\section{Discussion}

A variety of commercially available toothpastes with and without bleaching agents for home use were chosen for this study to evaluate color change, surface roughness and surface structure of tested teeth. The findings of this study revealed toothpastes containing blue covarine preparations had a measurable improvement in tooth whiteness which was significantly increased directly after toothbrushing in comparison to other products not containing blue covarine, including group II and III toothpastes, which showed a statistically significant color difference, $(\mathrm{p}=0.005$ and $\mathrm{p}=0.04$, respectively).

In the present work, it was revealed that the blue covarine-containing toothpaste was the only toothpaste tested to give a significant decrease in $b^{*}$ value and improvement in tooth whiteness $(\Delta \mathrm{E})$ in comparison to the controls. This decrease in $b^{*}$ value is mainly due to the deposition of the pigments on the enamel surface, which causes modification to the optical characters of the tooth surface ${ }^{22}$. The use of the blue pigment in toothpastes changes the observation of the yellow color in teeth by applying a thin, translucent blue layer on the tooth surface, thus creating a optical whitening effect. Yellow is opposite to blue in the spectrum of colors, thus a change or shift to blue creates an appearance which visually appears whiter by changing the net color towards white. This mechanism of whitening is built on many previous studies performed which showed that the blue shift of the yellow-blue axis $\left(b^{*}\right)$ is of higher significance in the observation of whiter teeth than other axis, $\left(\mathrm{L}^{*}\right)$ or $\left(\mathrm{a}^{*}\right)^{23-25}$.

There are contradictory results in the literature regarding the efficiency of blue covarine to provide an improved whitening result in teeth whiteness. Many past and recent studies showed instant and progressive whitening ${ }^{14,19,26-28}$; however, some other studies reported no whitening effect of the blue covarine formulations ${ }^{29,30}$. This contradiction in results might be due to using different techniques in recording the color change following brushing procedure which includes the use of either visual or instrumental tools. In the present study, a Vita Easyshade spectrophotometer was used to measure the color change as it proved in several studies to be more accurate than visual tools ${ }^{31,32}$.

In contrast, all other tooth pastes tested in this study had a relatively no significant change in $b^{*}$ and overall color change values $(\Delta \mathrm{E})$ when compared to the control groups. In this study, the tested toothpaste with $1 \%$ hydrogen peroxide (Colgate White now) presented a whitening effect similar to that of conventional toothpaste because it contains abrasive particles in the composition. During toothbrushing, the abrasive particles are trapped between the tips of the toothbrush bristles and the stained tooth surface. This was confirmed by results from the surface roughness experiment, where group III specimens had the highest increase in mean difference of surface roughness. Since the abrasive particles are physically harder than the superficial staining, this is removed leaving a clean tooth surface. Thus, the abrasive cleaning mechanism mainly influences the extrinsic stains and does not significantly affect any underlying intrinsic staining or the natural color of teeth ${ }^{33,34}$. 


\begin{tabular}{|c|c|c|c|c|}
\hline Toothpaste & Sample & $\begin{array}{l}\text { Average roughness } \\
(\mu \mathrm{m}) \text { BEFORE }\end{array}$ & $\begin{array}{l}\text { Average roughness } \\
(\mu \mathrm{m}) \text { AFTER }\end{array}$ & Difference \\
\hline \multirow{10}{*}{$\begin{array}{l}\text { Closeup white } \\
\text { now }\end{array}$} & A1 & 1.34 & 1.15 & -0.19 \\
\hline & A2 & 0.08 & 0.18 & 0.10 \\
\hline & A3 & 0.48 & 0.36 & -0.12 \\
\hline & A4 & 0.11 & 0.13 & 0.02 \\
\hline & A5 & 1.10 & 1.22 & 0.12 \\
\hline & A6 & 0.19 & 0.18 & -0.01 \\
\hline & A7 & 0.67 & 0.62 & -0.05 \\
\hline & A8 & 0.15 & 0.35 & 0.20 \\
\hline & A9 & 1.01 & 1.06 & 0.05 \\
\hline & A10 & 0.07 & 0.19 & 0.12 \\
\hline \multirow{10}{*}{$\begin{array}{l}\text { Sensodyne } \\
\text { true white }\end{array}$} & B1 & 0.08 & 0.29 & 0.21 \\
\hline & B2 & 0.38 & 0.32 & -0.06 \\
\hline & B3 & 0.42 & 0.39 & -0.03 \\
\hline & B4 & 0.17 & 0.19 & 0.02 \\
\hline & B5 & 0.07 & 0.30 & 0.23 \\
\hline & B6 & 0.37 & 0.32 & -0.05 \\
\hline & B7 & 0.49 & 0.42 & -0.07 \\
\hline & B8 & 0.22 & 0.21 & -0.01 \\
\hline & B9 & 0.27 & 0.28 & 0.01 \\
\hline & B10 & 0.37 & 0.31 & -0.06 \\
\hline \multirow{10}{*}{$\begin{array}{l}\text { Colgate optic } \\
\text { white }\end{array}$} & C1 & 0.64 & 0.74 & 0.10 \\
\hline & $\mathrm{C} 2$ & 0.14 & 0.49 & 0.35 \\
\hline & C3 & 0.14 & 0.09 & -0.05 \\
\hline & $\mathrm{C} 4$ & 0.27 & 0.23 & -0.04 \\
\hline & C5 & 0.67 & 0.88 & 0.21 \\
\hline & C6 & 0.13 & 0.49 & 0.36 \\
\hline & $\mathrm{C} 7$ & 0.08 & 0.70 & 0.62 \\
\hline & C8 & 0.29 & 0.31 & 0.02 \\
\hline & C9 & 0.74 & 0.88 & 0.14 \\
\hline & C10 & 0.12 & 0.53 & 0.41 \\
\hline \multirow[t]{10}{*}{ Closeup } & D1 & 0.38 & 0.45 & 0.07 \\
\hline & D2 & 0.37 & 0.22 & -0.15 \\
\hline & D3 & 1.27 & 0.49 & -0.78 \\
\hline & D4 & 0.74 & 0.54 & -0.20 \\
\hline & D5 & 0.38 & 0.45 & 0.07 \\
\hline & D6 & 0.30 & 0.18 & -0.12 \\
\hline & D7 & 1.11 & 1.22 & 0.11 \\
\hline & D8 & 0.75 & 0.73 & -0.02 \\
\hline & D9 & 0.47 & 0.54 & 0.07 \\
\hline & D10 & 0.30 & 0.18 & -0.12 \\
\hline \multirow[t]{10}{*}{ Sensodyne } & E1 & 0.31 & 0.35 & 0.04 \\
\hline & E2 & 1.87 & 0.73 & -1.14 \\
\hline & E3 & 0.43 & 0.42 & -0.01 \\
\hline & E4 & 0.30 & 0.25 & -0.05 \\
\hline & E5 & 0.35 & 0.34 & -0.01 \\
\hline & E6 & 2.04 & 0.60 & -1.44 \\
\hline & E7 & 0.18 & 0.29 & 0.11 \\
\hline & E8 & 0.30 & 0.25 & -0.05 \\
\hline & E9 & 0.26 & 0.33 & 0.07 \\
\hline & E10 & 1.23 & 0.72 & -0.51 \\
\hline
\end{tabular}




\begin{tabular}{|c|c|c|c|c|}
\hline Toothpaste & Sample & $\begin{array}{l}\text { Average roughness } \\
(\mu \mathrm{m}) \text { BEFORE }\end{array}$ & $\begin{array}{l}\text { Average roughness } \\
(\mu \mathrm{m}) \text { AFTER }\end{array}$ & Difference \\
\hline \multirow[t]{10}{*}{ Colgate } & F1 & 1.10 & 0.87 & -0.23 \\
\hline & $\mathrm{F} 2$ & 0.96 & 0.98 & 0.02 \\
\hline & F3 & 0.25 & 0.24 & -0.01 \\
\hline & $\mathrm{F} 4$ & 0.47 & 0.48 & 0.01 \\
\hline & F5 & 1.30 & 0.89 & -0.41 \\
\hline & F6 & 0.78 & 1.06 & 0.28 \\
\hline & F7 & 0.26 & 0.19 & -0.07 \\
\hline & F8 & 2.28 & 0.36 & -1.92 \\
\hline & F9 & 1.30 & 0.91 & -0.39 \\
\hline & F10 & 0.76 & 1.05 & 0.29 \\
\hline \multirow[t]{10}{*}{ Control } & G1 & 1.00 & 1.43 & 0.43 \\
\hline & G2 & 0.83 & 0.26 & -0.57 \\
\hline & G3 & 0.88 & 0.44 & -0.44 \\
\hline & G4 & 0.24 & 0.35 & 0.11 \\
\hline & G5 & 1.17 & 1.63 & 0.46 \\
\hline & G6 & 0.97 & 0.23 & -0.74 \\
\hline & G7 & 0.85 & 0.46 & -0.39 \\
\hline & G8 & 0.21 & 0.35 & 0.14 \\
\hline & G9 & 1.60 & 1.55 & -0.05 \\
\hline & G10 & 1.85 & 0.40 & -1.45 \\
\hline
\end{tabular}

\section{Mean difference of surface roughness}

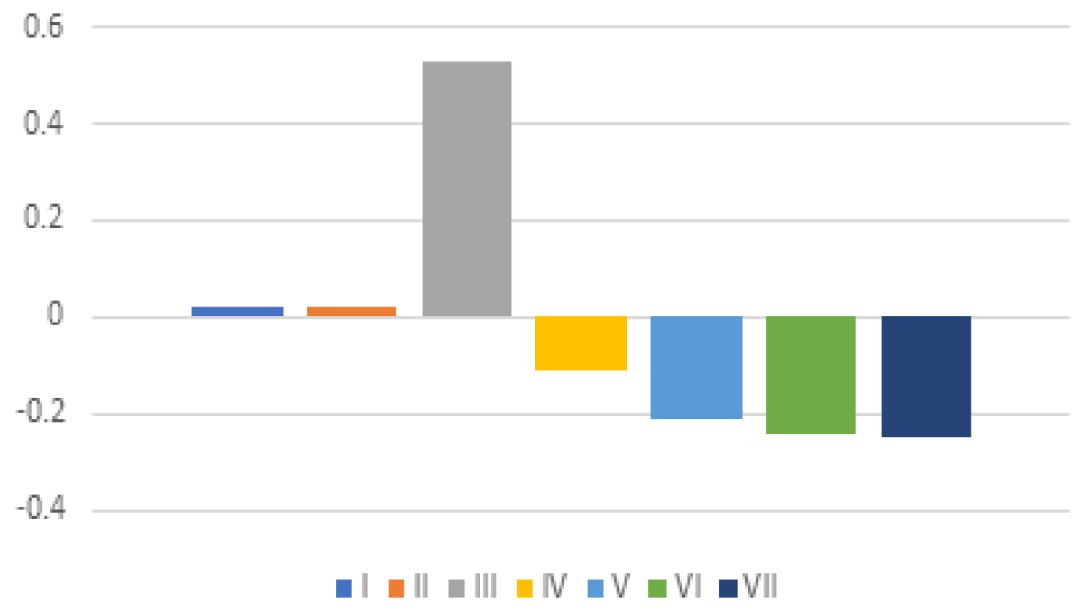

Figure 3. Mean differences in surface roughness of all groups.

This finding is consistent with previous studies that concluded that conventional dentifrices could outperform or have a similar whitening effect to whitening toothpaste $e^{30,35,36}$.

Concerning enamel surface roughness, Atomic force was not used to measure the surface roughness due to its limited measurement of an area of $25 \mu \mathrm{m}$ on a flat area only, whereas a white light interferometer was used in this study due to its wider area measurement ( $2 \mathrm{~mm} \times 2 \mathrm{~mm}$ ) and ability to assess non-flat surfaces, which is superior to the properties of atomic force.

Although there were no statistically significant differences between all groups in our study, group III toothpaste created the roughest surface, while group VI toothpaste resulted in the smoothest surface in comparison to control group. This change in physical properties can occur due to effects of demineralization 

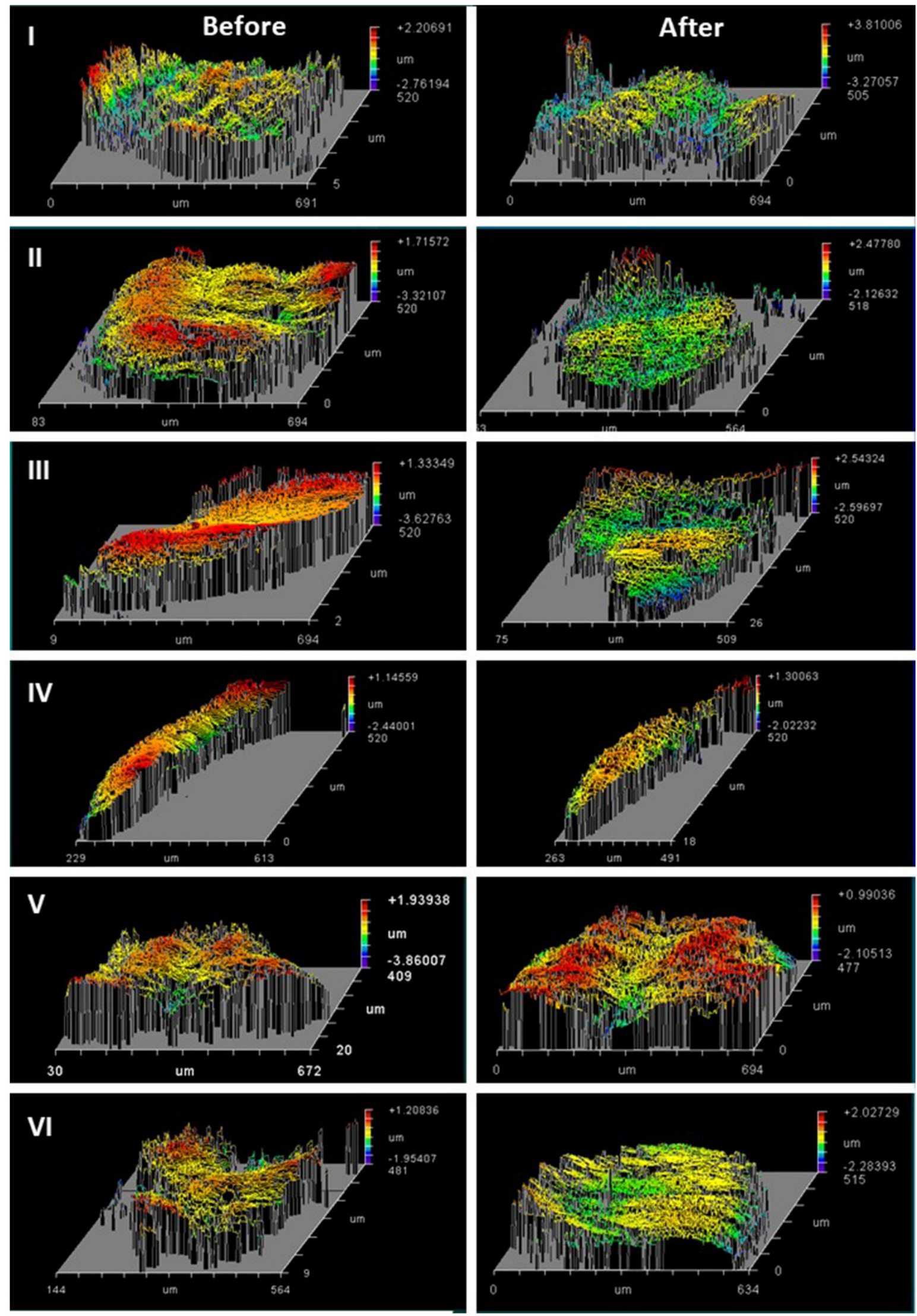

Figure 4. White light interferometer images of all groups before and after brushing procedure. 


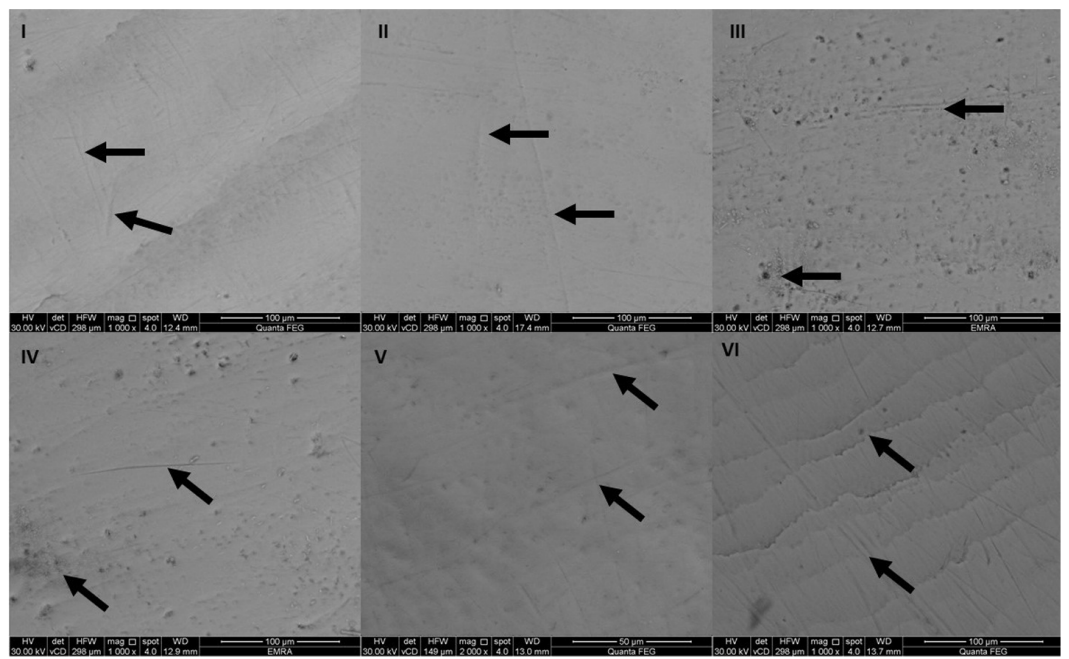

Figure 5. SEM micrographs of experimental groups after brushing procedure. Groups I and II show smooth enamel surface with fine scratches (arrows). Group III shows irregular enamel with deeper surface scratches and pores (arrows). Groups IV, V and VI show fine surface scratches and few pores (arrows).

and remineralization of enamel surface ${ }^{37}$. This demineralization can be caused by diffusion of hydrogen peroxide found in the toothpaste in group III.

The previous results of color change and surface roughness are consistent with the study performed by Vieira-Junior et al., which showed that the alteration in surface roughness has no significant correlation with $\mathrm{b}^{*}$ values or significant alteration in the general color change represented by $\Delta \mathrm{E}$ values ${ }^{38}$.

In the present study, it was aimed to compare the changes caused by different toothpastes with different compositions on human enamel surface with SEM and visualize the structural changes with photomicrographs. Specimens of the control group revealed a normal enamel surface, while that of groups I and II showed minor changes of the enamel surfaces manifested as fine scratches. However, group III specimens showed some alteration in the enamel surface manifested as surface irregularities, few pores and the scratches became more obvious.

\section{Conclusion}

From the results of the current study it can be considered that toothpastes with blue covarine are both an effective and a safe method to improve the whiteness of teeth in the routine home tooth brushing.

\section{Data availability}

Figshare: tooth color (Influence of different types of whitening tooth pastes on the tooth color, enamel surface roughness and enamel morphology of human teeth). https://doi. org/10.6084/m9.figshare.9923756.v120.

This project contains the following underlying data:

- tooth color (Influence of different types of whitening tooth pastes on the tooth color, enamel surface roughness and enamel morphology of human teeth).xlsx

- surface roughness (Influence of different types of whitening tooth pastes on the tooth color, enamel surface roughness and enamel morphology of human teeth).xlsx

Figshare: Influence of different types of whitening tooth pastes on the tooth color, enamel surface roughness and enamel morphology of human teeth. https://doi.org/10.6084/ m9.figshare.9923780.v121.

This project contains raw scanning electron microscopy and white light interferometry images for each group.

Data are available under the terms of the Creative Commons Attribution 4.0 International license (CC-BY 4.0).
1. Van der Geld P, Oosterveld P, Van Heck G, et al: Smile attractiveness. Selfperception and influence on personality. Angle Orthod. 2007; 77(5): 759-765. PubMed Abstract | Publisher Full Text

2. Samorodnitzky-Naveh GR, Geiger SB, Levin L: Patients' satisfaction with dental esthetics. J Am Dent Assoc. 2007: 138(6): 805-808.

PubMed Abstract | Publisher Full Text
3. Tin-Oo MM, Saddki N, Hassan N: Factors influencing patient satisfaction with dental appearance and treatments they desire to improve aesthetics. BMC Oral dental appear

PubMed Abstract | Publisher Full Text | Free Full Text

4. Silvola AS, Varimo M, Tolvanen M, et al.: Dental esthetics and quality of life in adults with severe malocclusion before and after treatment. Angle Orthod. 
2014; 84(4): 594-599

PubMed Abstract | Publisher Full Text

5. Xiao J, Zhou XD, Zhu WC, et al: The prevalence of tooth discolouration and the self-satisfaction with tooth colour in a Chinese urban population. $J$ Oral Rehabil. 2007; 34(5): 351-360.

PubMed Abstract | Publisher Full Text

6. Mehl C, Wolfart S, Vollrath $\mathrm{O}$, et al.: Perception of dental esthetics in different cultures. Int J Prosthodont. 2014; 27(6): 523-529.

PubMed Abstract | Publisher Full Text

7. Al-Zarea BK: Satisfaction with appearance and the desired treatment to improve aesthetics. Int J Dent. 2013; 2013: 912368.

PubMed Abstract | Publisher Full Text | Free Full Text

8. Joiner A: Whitening toothpastes: a review of the literature. J Dent. 2010 38(Suppl 2): e17-24.

PubMed Abstract | Publisher Full Text

9. Kwon SR, Wertz PW: Review of the Mechanism of Tooth Whitening. J Esthet Restor Dent. 2015; 27(5): 240-257. PubMed Abstract | Publisher Full Text

10. Carey CM: Tooth whitening: what we now know. J Evid Based Dent Pract. 2014; 14 Suppl: $70-76$.

PubMed Abstract | Publisher Full Text | Free Full Text

11. Soares CN, Amaral FL, Mesquita MF, et al.: Toothpastes containing abrasive and chemical whitening agents: efficacy in reducing extrinsic dental staining. Gen Dent. 2015; 63(6): e24-28.

PubMed Abstract

12. Casado BGS, Moraes SLD, Souza GFM, et al:: Efficacy of Dental Bleaching with Whitening Dentifrices: A Systematic Review. Int J Dent. 2018; 2018: 7868531. PubMed Abstract | Publisher Full Text | Free Full Text

13. Alman DH: Colour Physics for Industry, edited by Roderick McDonald, Society of Dyers and Colourists, Bradford, England, 1987, 301 pp., paperbound. Price £ 20.00. Color Research \& Application. 1988; 13(4): 264-265. Publisher Full Text

14. Tao D, Smith RN, Zhang Q, et al:: Tooth whitening evaluation of blue covarine containing toothpastes. J Dent. 2017; 67S: S20-S24. PubMed Abstract | Publisher Full Text

15. Bergesch $\mathrm{V}$, Baggio Aguiar FH, Turssi $\mathrm{CP}$, et al:: Shade changing effectiveness of plasdone and blue covarine-based whitening toothpaste on teeth stained with chlorhexidine and black tea. Eur J Dent. 2017; 11(4): 432-437. PubMed Abstract | Publisher Full Text | Free Full Text

16. Jiang N, Zhang C, Agingu C, et al.: Comparison of Whitening Dentifrices on the Effectiveness of In-office Tooth Bleaching: A Double-blind Randomized Controlled Clinical Trial. Oper Dent. 2019; 44(2): 138-145. PubMed Abstract | Publisher Full Text

17. Westland S, Luo W, Li Y, et al.: Investigation of the perceptual thresholds of tooth whiteness. $J$ Dent 2017; 67S: S11-S14. PubMed Abstract | Publisher Full Text

18. Philpotts CJ, Cariddi E, Spradbery PS, et al.: In vitro evaluation of a silica whitening toothpaste containing blue covarine on the colour of teeth containing anterior restoration materials. J Dent. 2017; 67S: S29-S33. PubMed Abstract | Publisher Full Text

19. Tao D, Sun JN, Wang X, et al:: In vitro and clinical evaluation of optical tooth whitening toothpastes. J Dent. 2017; 67s: S25-s28. PubMed Abstract | Publisher Full Tex

20. Al-Ankily M, shamel m, Bakr M: tooth color (Influence of different types of whitening tooth pastes on the tooth color, enamel surface roughness and enamel morphology of human teeth).xIsx. figshare. Dataset. 2019. http://www.doi.org/10.6084/m9.figshare.9923756.v1

21. shamel $\mathrm{m}, \mathrm{Al}$-Ankily M, Bakr M: Influence of different types of whitening tooth pastes on the tooth color, enamel surface roughness and enamel morphology of human teeth. figshare. Figure. 2019. http://www.doi.org/10.6084/m9.figshare.9923780.v1

22. Oliveira M, Fernandez E, Bortolatto J, et al.: Optical Dental Whitening Efficacy of
Blue Covarine Toothpaste in Teeth Stained by Different Colors. $J$ Esthet Restor Dent. 2016; 28 Suppl 1: S68-77.

PubMed Abstract | Publisher Full Text

23. Kleber CJ, Putt MS, Nelson BJ: In vitro tooth whitening by a sodium bicarbonate/peroxide dentifrice. J Clin Dent. 1998; 9(1): 16-21. PubMed Abstract

24. Gerlach RW, Gibb RD, Sagel PA: A randomized clinical trial comparing a nove $5.3 \%$ hydrogen peroxide whitening strip to $10 \%, 15 \%$, and $20 \%$ carbamide peroxide tray-based bleaching systems. Compend Contin Educ Dent Suppl. 2000; (29): S22-28; quiz S42-23. PubMed Abstract

25. Gerlach RW, Barker ML, Sagel PA: Objective and subjective whitening respons of two self-directed bleaching systems. Am J Dent. 2002; 15(Spec No): 7A-12A. PubMed Abstract

26. Collins LZ, Naeeni M, Platten SM: Instant tooth whitening from a silica toothpaste containing blue covarine J Dent. 2008; 36 Suppl 1: S21-25. PubMed Abstract | Publisher Full Text

27. Joiner A, Philpotts CJ, Alonso C, et al:: A novel optical approach to achieving tooth whitening. J Dent. 2008; 36(Suppl 1): S8-14. PubMed Abstract | Publisher Full Text

28. Vaz VTP, Jubilato DP, Oliveira MRM, et al:: Whitening toothpaste containing activated charcoal, blue covarine, hydrogen peroxide or microbeads: which one is the most effective? J Appl Oral Sci. 2019; 27: e20180051. PubMed Abstract | Publisher Full Text | Free Full Text

29. Torres CR, Perote LC, Gutierrez NC, et al.: Efficacy of mouth rinses and toothpaste on tooth whitening. Oper Dent. 2013; 38(1): 57-62. PubMed Abstract | Publisher Full Text

30. Horn BA, Bittencourt BF, Gomes OM, et al:: Clinical evaluation of the whitening effect of over-the-counter dentifrices on vital teeth. Braz Dent J. 2014; 25(3): 203-6.

PubMed Abstract | Publisher Full Text

31. Liberato WF, Barreto IC, Costa PP, et al: A comparison between visual, intraora scanner, and spectrophotometer shade matching: A clinical study. J Prosthet Dent. 2019; 121(2): 271-275.

PubMed Abstract | Publisher Full Tex

32. Chitrarsu VK, Chidambaranathan AS, Balasubramaniam M: Analysis of Shade Matching in Natural Dentitions Using Intraoral Digital Spectrophotometer in LED and Filtered LED Light Sources. J Prosthodont. 2019; 28(1): e68-e73. PubMed Abstract | Publisher Full Text

33. Ganss C, Marten J, Hara AT, et al:: Toothpastes and enamel erosion/abrasion Impact of active ingredients and the particulate fraction. J Dent. 2016; 54: $62-67$.

PubMed Abstract | Publisher Full Text

34. Patil PA, Ankola AV, Hebbal Ml, et al.: Comparison of effectiveness of abrasive and enzymatic action of whitening toothpastes in removal of extrinsic stains - a clinical trial. Int J Dent Hyg. 2015; 13(1): 25-29. PubMed Abstract | Publisher Full Text

35. Jurema AL, Claudino ES, Torres CR, et al:: Effect of Over-the-counter Whitening Products associated or Not with $10 \%$ Carbamide Peroxide on Color Change and Microhardness: in vitro Study. J Contemp Dent Pract. 2018; 19(4): 359-366. PubMed Abstract | Publisher Full Text

36. Pintado-Palomino K, Vasconcelos CV, Silva RJ, et al.: Effect of whitening dentifrices: a double-blind randomized controlled trial. Braz Oral Res. 2016 30(1): e82.

PubMed Abstract | Publisher Full Text

37. Sasaki RT, Catelan A, Bertoldo Edos S, et al:: Effect of $7.5 \%$ hydrogen peroxide containing remineralizing agents on hardness, color change, roughness and micromorphology of human enamel. Am J Dent. 2015; 28(5): 261-7. PubMed Abstract

38. Vieira-Junior WF, Vieira I, Ambrosano GM, et al.: Correlation between alteration of enamel roughness and tooth color. J Clin Exp Dent. 2018; 10(8): e815-e820. PubMed Abstract | Publisher Full Text | Free Full Text 


\section{Open Peer Review}

\section{Current Peer Review Status:}

\section{Version 1}

Reviewer Report 06 December 2019

https://doi.org/10.5256/f1000research.22891.r55277

(C) 2019 Ullah R. This is an open access peer review report distributed under the terms of the Creative Commons Attribution License, which permits unrestricted use, distribution, and reproduction in any medium, provided the original work is properly cited.

\section{Rizwan Ullah}

Sindh Institute of Oral Health Sciences, Jinnah Sindh Medical University, Karachi, Pakistan

The title of the study is quite lengthy. It is suggested to the authors to reduce the length of article title.

Does the blue covarine toothpaste have any additional whitening agent in its composition?

In methods, instead of sterilized artificial saliva write "sterile saliva".

In Figure 1, please recheck the labelling, especially B and D.

In the discussion, give a brief account of the limitations of your study.

Overall the study was well performed and showed some interesting results. The standardized brushing method was a very good way to ensure the accuracy of the results of the experiment. Statistical analysis of data is available and appropriately interpreted. However some minor suggestions could be taken into consideration: Further analysis between the results of different groups, e.g group II, III and IV could have added to the study. Overall, the study was clear and well written.

Is the work clearly and accurately presented and does it cite the current literature? Yes

Is the study design appropriate and is the work technically sound? Yes

Are sufficient details of methods and analysis provided to allow replication by others? Yes

If applicable, is the statistical analysis and its interpretation appropriate? 
Yes

Are all the source data underlying the results available to ensure full reproducibility? Yes

Are the conclusions drawn adequately supported by the results?

Yes

Competing Interests: No competing interests were disclosed.

Reviewer Expertise: Oral Biology and Dental materials.

I confirm that I have read this submission and believe that I have an appropriate level of expertise to confirm that it is of an acceptable scientific standard.

Reviewer Report 06 December 2019

https://doi.org/10.5256/f1000research.22891.r57522

(c) 2019 Serag M. This is an open access peer review report distributed under the terms of the Creative Commons Attribution License, which permits unrestricted use, distribution, and reproduction in any medium, provided the original work is properly cited.

\section{Mahmoud Serag}

Prosthodontics Division, General Dentistry Department, School of Dental Medicine, East Carolina University (ECU), Greenville, NC, USA

The present study investigated the effect of different types of tooth pastes on the enamel surface properties.

The introduction section was informative, brief and well written. The authors highlighted the numerical evaluation of color as well as the different methods and materials for tooth whitening using tooth pastes at home.

The white light inteferometer used to measure surface roughness is an accurate method which ensured reliable results. The same applies to the brushing apparatus used although it was not clear the type of tooth brush used nor the frequency of changing the tooth brush.

Different formulations of the investigated tooth pastes were not fully written.

The results were clear and the SEM micrographs were explained thoroughly. However, more statistical analysis could have been added to compare between more experimental groups, not only with the control.

The discussion was written well and explained the outcomes of the research.

Overall the present research was written and executed well with clear results. 
Is the work clearly and accurately presented and does it cite the current literature? Yes

Is the study design appropriate and is the work technically sound?

Yes

Are sufficient details of methods and analysis provided to allow replication by others?

Yes

If applicable, is the statistical analysis and its interpretation appropriate?

Yes

Are all the source data underlying the results available to ensure full reproducibility?

Yes

Are the conclusions drawn adequately supported by the results?

Yes

Competing Interests: No competing interests were disclosed.

Reviewer Expertise: Prosthodontic Dentistry

I confirm that I have read this submission and believe that I have an appropriate level of expertise to confirm that it is of an acceptable scientific standard.

Reviewer Report 22 October 2019

https://doi.org/10.5256/f1000research.22891.r55473

(C) 2019 Hassan R. This is an open access peer review report distributed under the terms of the Creative Commons Attribution License, which permits unrestricted use, distribution, and reproduction in any medium, provided the original work is properly cited.

\section{Rania Mossad Hassan}

${ }^{1}$ Faculty of Dentistry, Ain Shams University, Cairo, Egypt

2 Badr University, Cairo, Egypt

This study investigated the effect of different whitening toothpastes on the teeth enamel color surface roughness and morphology.

The topic is interesting and the manuscript is well written and well constructed. The introduction was informative and covered the main ideas investigated in the study.

The apparatus used to simulate the brushing provided a standardized procedure thus aiding in having accurate results. 
All data of teeth color and surface roughness are available.The discussion was well written and covered and explained the results thoroughly.

However, some minor comments are suggested for the authors to consider:

More than one type of tooth pastes with blue covarine could have been tested to compare their efficacy, or different concentrations of blue covarine.

The authors didn`t mention if a new toothbrush was used in the experiment for each tooth or not.

In figure 2 the word "colour" is different than the spelling in the rest of the research.

Is the work clearly and accurately presented and does it cite the current literature? Yes

Is the study design appropriate and is the work technically sound?

Yes

Are sufficient details of methods and analysis provided to allow replication by others? Yes

If applicable, is the statistical analysis and its interpretation appropriate? Yes

Are all the source data underlying the results available to ensure full reproducibility? Yes

Are the conclusions drawn adequately supported by the results?

Yes

Competing Interests: No competing interests were disclosed.

Reviewer Expertise: Oral Biology

I confirm that I have read this submission and believe that I have an appropriate level of expertise to confirm that it is of an acceptable scientific standard. 
The benefits of publishing with F1000Research:

- Your article is published within days, with no editorial bias

- You can publish traditional articles, null/negative results, case reports, data notes and more

- The peer review process is transparent and collaborative

- Your article is indexed in PubMed after passing peer review

- Dedicated customer support at every stage

For pre-submission enquiries, contact research@f1000.com 